\title{
DEGRADACIÓN AERÓBICA DE TNT (2,4,6 - TRINITROTOLUENO) POR UN CONSORCIO BACTERIANO AISLADO DE AMBIENTES CONTAMINADOS
}

\author{
AEROSTIC DEGRADATION OF TNT (2,4,6-TRINITROTOLUENE) BY A BACTERIAL CONSORTIUM \\ ISOLATED FROM CONTAMINATED ENVIRONMENTS
}

\author{
${ }^{1}$ Claudia Marín Catacora, ${ }^{2}$ Yerson Durán Ramirez; ${ }^{3}$ Pablo Ramírez Roca, ${ }^{4}$ Daladier Castillo Cotrina
}

\begin{abstract}
RESUMEN
En el presente trabajo se ensayó una técnica de degradación biológica del explosivo 2,4,6 trinitrotolueno (TNT) en condiciones in vitro. Se realizó un screening de cepas bacterianas degradadoras de TNT a partir de 18 cepas provenientes de suelo contaminado con derivados de hidrocarburo y de un sistema de tratamiento de relaves mineros. Se seleccionaron dos cepas: UP1 y 3T412C, identificadas por análisis de la secuencia parcial del gen rRNA 16S como Serratia marcescens UP1 y Klebsiella oxytoca 3T412C con los que se formó un consorcio evaluándose la degradación de $60 \mathrm{mg} / \mathrm{l} \mathrm{de}$ TNT en medio Mínimo Modificado con succinato como única fuente de carbono a temperatura ambiente $\left(28 \pm 2{ }^{\circ} \mathrm{C}\right)$ en agitación constante a $150 \mathrm{rpm}$ por 72 horas. La concentración de TNT del medio de cultivo fue cuantificada por Cromatografía Líquida de Alta Eficacia (HPLC). El porcentaje de degradación de TNT para Klebsiella oxytoca 3T412C fue $97,87 \%$, para el consorcio $95,81 \%$ y para Serratia marcescensUP1 $42,94 \%$ tras 72 horas de incubación. En conclusión, estos resultados demuestran la presencia de bacterias degradadoras de TNT con potencial para ser empleadas en procesos de biorremediación.
\end{abstract}

Palabras clave: Consorcio, degradación aeróbica, Klebsiella oxytoca, Serratia marcescens, 2,4,6-trinitrotolueno (TNT)

\section{ABSTRACT}

In the present work a biological degradation technique of the explosive 2,4,6 trinitrotoluene (TNT) was tested under in vitro conditions. A screening of TNT-degrading bacterial strains was carried out from 18 strains from soil contaminated with hydrocarbon derivatives and from a tailings treatment system. Two strains were selected: UP1 and 3T412C, identified by analysis of the partial sequence of the 16S rRNA gene such as Serratia marcescens UP1 and Klebsiella oxytoca 3T412C with which a consortium was formed evaluating the degradation of $60 \mathrm{mg} / 1$ of TNT in Modified Minimum Medium with succinate as the sole charcoal source at room temperature $\left(28 \pm 2{ }^{\circ} \mathrm{C}\right)$ under constant agitation at $150 \mathrm{rpm}$ for 72 hours. The TNT concentration of the culture medium was quantified by High Efficiency Liquid Chromatography (HPLC). The degradation percentage of TNT for Klebsiella oxytoca 3T412C was $97,87 \%$, for the consortium $95,81 \%$ and for Serratia marcescens UP1 $42,94 \%$ after 72 hours of incubation. In conclusion, these results demonstrate the presence of TNT degrading bacteria with potential to be used in bioremediation processes.

Keywords: Consortium, aerobic degradation, Klebsiella oxytoca, Serratia marcescens, 2,4,6-trinitrotoluene (TNT)

\footnotetext{
${ }^{1}$ Consultora independiente. E-mail: claudiamaritac@gmail.com

${ }^{2}$ Organismo Nacional de Sanidad Pesquera. E-mail; yersonduran26@gmail.com

${ }^{3}$ Universidad Nacional Mayor de San Marcos, Lima-Perú. E-mail: pabloramirezroca@gmail.com

${ }^{4}$ Universidad Nacional Jorge Basadre Grohmann, Lima-Perú. E-mail: daladiercastillo@hotmail.com
} 


\section{INTRODUCCIÓN}

El incremento de los contaminantes orgánicos que son desechados por las industrias pueden causar muchos problemas relacionados a la salud y al medio ambiente, esta preocupación ha incrementado la investigación de diversas estrategias que puedan emplearse para remediar el daño causado (Pandey y Rakesh, 2002).

En este contexto, el TNT se encuentra clasificado como contaminante prioritario, por lo cual, los residuos generados durante su fabricación, transporte y almacenamiento deben tener una regulación especial (EPA, 2001). Este es un explosivo recalcitrante en el ambiente y tóxico para los seres vivos; sin embargo, los microorganismos han desarrollado estrategias para su degradación tanto en condiciones aerobias como anaerobias, siendo los principales protagonistas en la remediación de lugares contaminados cuando se les suministra las condiciones favorables para tal cometido.

La existencia de microorganismos con actividad degradadora de 2,4,6-trinitrotolueno (TNT) ha sido descrita, entre ellos, a bacterias como Pseudomonas fluorescens I-C (Pak et al., 2000), P. putida (Cho et al., 2008), $P$. pseudoalcaligenes JS52 (Fiorella y Spain, 1997), Clostridium acetobutylicum (Watrous et al., 2003), Escherichia coli (Stenuit et al., 2009) y la levadura Yarrowia lipolytica (Ziganshin et al., 2007). Estos microorganismos han desarrollado mecanismos metabólicos para la degradación de 2,4,6trinitrotolueno. Los principales subproductos son 2amino-4.6-dinitrotolueno y 2.2-azoxy-tolueno que se acumulan como subproductos principales a través de sustancias intermedias como 2-hidroxilamino-4,6dinitrotolueno (2HADNT), 2.4-diamino-6nitrotolueno (2,4DANT); dinitrotolueno (DNT) y nitrotolueno (NT) y 3.5-dinitroanilino (3,5DNA), lo que indica la existencia de varias rutas de degradación del TNT (Oh et al., 2003).

La amplia distribución de microorganismos degradantes de TNT y la abundancia de las vías catabólicas que pueden conducir a su transformación y mineralización lo que proporciona una oportunidad para la optimización de las propiedades catabólicas de estos (Esteve et al., 2001; Fritsche y Hofrichter, 2000, Chien et al., 2014).

La investigación planteó identificar, molecularmente, bacterias que degradan 2,4,6-trinitrotolueno y evaluar su capacidad de degradación y, según estos resultados, conformar un consorcio cuya actividad fue comparado con las cepas, originalmente, aisladas, esperando que la asociación formada muestre un mayor porcentaje de biodegradación de TNT.

\section{MATERIAL Y MÉTODOS}

\section{Material biológico}

18 cepas bacterianas, aisladas de aguas y suelos de ambientes mineros de las regiones La Libertad, Lima y zonas petroleras de la región Ucayali (Pucallpa), pertenecientes al cepario del Laboratorio de Microbiología Molecular y Biotecnología de la Facultad de Ciencias Biológicas de la Universidad Nacional Mayor de San Marcos.

Obtención del inóculo bacteriano y preselección Se reactivaron las 18 cepas bacterianas en $1,5 \mathrm{ml}$ de TSB (Caldo Soya Tripticasa), incubándose durante 24 horas a temperatura ambiente $\left(28^{\circ} \mathrm{C} \pm 2^{\circ} \mathrm{C}\right)$ los que se centrifugaron a $10000 \mathrm{rpm} \times 5$ minutos y se lavaron 2 veces con solución salina al $0,85 \%$ y se inocularon a $10 \mathrm{ml}$ de medio de cultivo Mínimo Modificado (M.M.) (Durán, 2013), constituido por $(\mathrm{g} / \mathrm{l}) \mathrm{K}_{2} \mathrm{HPO}_{4}(1,68)$, $\mathrm{MgSO}_{4}(0,12), \mathrm{NaCl}(0,5), \mathrm{KOH}(7,5)$, Ácido succínico $(6,5)$ a pH 7,05 conteniendo $20 \mathrm{mg} / 1$ de TNT como concentración final, incubado a temperatura ambiente sobre un agitador orbital a $150 \mathrm{rpm}$ durante 10 días, luego subcultivados dos veces cada cinco días en $10 \mathrm{ml}$ de M.M., aumentando la concentración hasta $40 \mathrm{mg} / 1$ y $60 \mathrm{mg} / 1 \mathrm{de}$ TNT. Se preseleccionaron las cepas que presentaron crecimiento en los 3 subcultivos conservándolas en cepario a $4^{\circ} \mathrm{C}$.

\section{Selección de las cepas bacterianas degradadoras de} TNT y formación del consorcio

Las cepas preseleccionadas se inocularon a $100 \mathrm{ml}$ de M.M. a 0,5 McFarland. El medio fue incubado a temperatura ambiente durante 48 horas sobre un agitador orbital a $150 \mathrm{rpm}$ a temperatura ambiente $\left(28^{\circ} \mathrm{C} \pm 2^{\circ} \mathrm{C}\right)$ evaluándose la cantidad de TNT residual, nitritos y antagonismo entre las cepas y crecimiento poblacional con una cámara Petroff-Hausser.

\section{Cuantificación de TNT residual}

Se aplicó el método 8330B del EPA utilizado para el análisis de muestras de agua con nitroaromáticos, nitroamidas y ésteres de nitrato mediante la técnica de HPLC RP (fase reversa). Las condiciones de corrida fueron establecidas según el protocolo de Merck recomendado para el análisis de aguas. El equipo utilizado fue un HPLC VWR Hitachi Chromaster 5430 Diode Array Detector. La fase inmóvil consistió en una columna cromatográfica de sílica Purospher (B) RP-18 HC y como fase móvil una mezcla formada por acetonitrilo y metanol $(20: 80 \mathrm{v} / \mathrm{v})$ y como buffer sodiodihidrogenofosfato $(\mathrm{c}=0,01 \mathrm{~mol} / \mathrm{l}, \mathrm{pH} 4,5) \mathrm{con}$ una velocidad de flujo de $0,8 \mathrm{ml} / \mathrm{min}$ con un tiempo de corrida de 70 minutos por muestra y leído en un detector de diodos (DAD) a $230 \mathrm{~nm}$.

\section{Detección de nitritos en el medio de cultivo}

Se trabajó con el método de Fries y Getrost (1977). Se tomó $2,5 \mathrm{ml}$ de muestra y se mezcló con $250 \mathrm{ul} \mathrm{de}$ ácido sulfanílico y se homogenizó por agitación de 2 a 4 minutos. Luego se agregó 250 ul de $\alpha$-naftilamina, 250 ul de acetato de sodio al $25 \%$ y $2,5 \mathrm{ml}$ de ácido 
acético glacial. Después de estabilizarse la reacción por 10 minutos, se leyó la absorbancia en el espectrofotómetro a $520 \mathrm{~nm}$.

\section{Pruebas de antagonismo}

Se aplicó la técnica de Gauze modificada para evaluar la interacción entre las bacterias (Orjuela et al., 2003; Varón, 2013). La prueba consistió en dividir en dos segmentos a una placa Petri con Agar Soya Tripticasa (TSA) y otra placa con M.M. sólido, en el cual se sembró cada cepa masivamente, de tal manera que el estriado quedará enfrentada una con respecto a otra.

Identificación molecular de las bacterias degradadoras de TNT

Para la extracción de DNA cromosómico, se siguió el protocolo del Wizard Genomic DNA Purification Kit (Promega $®)$. Se emplearon los iniciadores 27F (5'AGA GTT TGA TCM TGG CTC AG-3') con1492R (5'-TAC GGY TAC CTT GTT ACG ACTT-3') y 518F (CCA GCA GCC GCG GTA ATA CG) con 800R (TAC CAG GGT ATC TAA TCC). La reacción de PCR consistió en: desnaturalización inicial $94{ }^{\circ} \mathrm{C}$ por 2 minutos, 34 ciclos de desnaturalización a $94{ }^{\circ} \mathrm{C}$ por 1 minuto, hibridación a $55^{\circ} \mathrm{C}$ por 1 minuto, amplificación a $72{ }^{\circ} \mathrm{C}$ por 2 minutos y amplificación final a $72^{\circ} \mathrm{C}$ por $10 \mathrm{~min}$.

Los amplificados fueron secuenciados por MACROGEN KOREA. Posteriormente, las secuencias fueron alineadas con el programa BioEdit 7.0.9, luego comparadas con la base de datos del GenBank/EMBL/DDBJ, usando la plataforma del programa local de alineamiento de secuencias BlastN versión 2,0. Seguidamente, se realizó un alineamiento múltiple con el programa BioEdit 7.0.9 con secuencias que presentaron similitud mayor o igual a $97 \%$ y Valor E 0,0 .

Finalmente, se construyó el árbol filogenético con el programa Mega 5,0, empleando el método de Neighbor-Joining con un modelo Compuesto de Máxima Verosimilitud.

\section{Análisis estadístico}

Los valores de degradación de TNT mostrados por las bacterias seleccionadas $y$ el consorcio fueron sometidos al análisis del ANVA, posteriormente a la prueba de Tuckey para establecer quién presentó el mayor porcentaje de degradación de TNT.

\section{RESULTADOS}

\section{Preselección de las cepas}

Las 18 cepas evaluadas mostraron divergencias en el crecimiento (alto, medio, bajo) y variabilidad en los colores del medio de cultivo (crema, amarillo, naranja); sin embargo, las cepas preseleccionadas corresponden a las que mostraron uniformidad en la turbidez en los 3 subcultivos con 20 , 40 y $60 \mathrm{mg} / 1$, siendo estas las cepas UP1, UP10, 3T412C y 2 T431.

\section{Análisis de la degradación de TNT de las cepas preseleccionadas \\ Los mayores valores de TNT degradado efectivo fueron para $3 \mathrm{~T} 412 \mathrm{C} 91,47 \%$ y UP1 con $37,83 \%$, mientras que $2 \mathrm{~T} 431$ obtuvo el menor porcentaje con $6,77 \%$ (tabla 1$)$.}

Cepas bacterianas seleccionadas y formación del consorcio

Las cepas seleccionadas fueron $3 \mathrm{~T} 412 \mathrm{C}$ y UP1 que no presentaron antagonismo tras la realización de la prueba de Gauze en medio TSA y M.M. sólido. Además, en M.M. agarificado desarrollaron tenue crecimiento celular a comparación de en TSA.

Nitrito liberado por las cepas seleccionadas y el consorcio

La cepa 3T412C liberó $0,4 \mathrm{mg} / 1$ de nitrito en 24 horas y a las 48 y 72 horas no se detectó. El consorcio mostró un comportamiento similar, pues se detectó $0,4 \mathrm{mg} / 1$ en 24 horas y $0,1 \mathrm{mg} / 1$ en 48 horas. En cambio, UP1 mostró un incremento de nitrito en el medio de cultivo hasta las 72 horas (figura 1).

Tabla 1. Degradación de TNT paracada cepa bacterianapreseleccionada a las 0 y 48 horas determinado por HPLC

\begin{tabular}{|c|c|c|c|c|c|c|}
\hline \multirow[b]{2}{*}{ CEPA } & \multicolumn{2}{|c|}{0 Horas } & \multicolumn{2}{|c|}{48 Horas } & \multirow{2}{*}{$\begin{array}{c}\text { TNT } \\
\text { degradado } \\
\text { efectivo } \\
\text { (mg/l) }\end{array}$} & \multirow{2}{*}{$\begin{array}{c}\text { Porcentaje } \\
\text { de TNT } \\
\text { degradado } \\
\text { efectivo }(\%)\end{array}$} \\
\hline & $\begin{array}{c}\text { TNT } \\
\text { Residual } \\
\text { (mg/l) } \\
\end{array}$ & $\begin{array}{c}\text { TNT } \\
\text { degradado } \\
(\mathrm{mg} / \mathrm{l})\end{array}$ & $\begin{array}{c}\text { TNT } \\
\text { Residual } \\
\text { (mg/l) }\end{array}$ & $\begin{array}{c}\text { TNT } \\
\text { degradado } \\
(\mathrm{mg} / \mathrm{l})\end{array}$ & & \\
\hline $3 \mathrm{~T} 412 \mathrm{C}$ & 60 & 0 & 1,40 & 58,76 & 54,80 & 91,47 \\
\hline UP1 & 60 & 0 & 33,42 & 26,58 & 22,70 & 37,83 \\
\hline UP10 & 60 & 0 & 35,64 & 24,36 & 20,48 & 34,13 \\
\hline 2T431 & 60 & 0 & 52,06 & 7,94 & 4,06 & 6,77 \\
\hline CONTROL & 60 & 0 & 56,12 & 3,88 & 0 & 0 \\
\hline
\end{tabular}

Fuente: Elaboración propia 


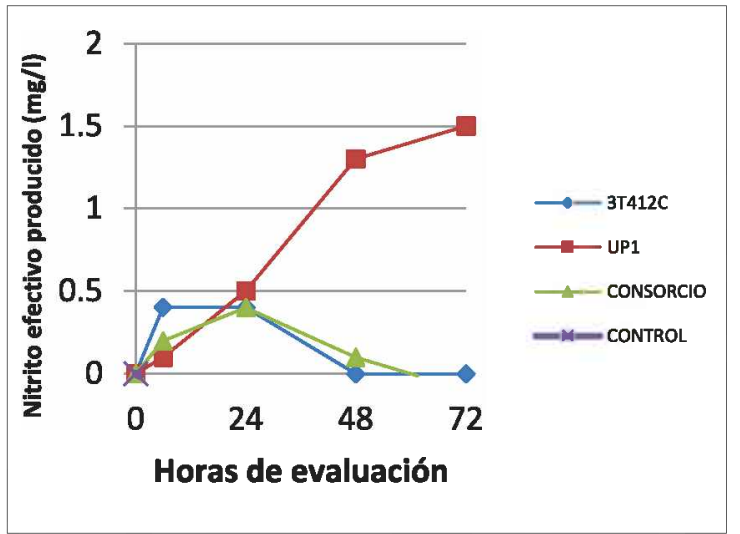

Figura 1. Nitrito efectivo producido por las cepas y el consorcio.

Fuente: Elaboración propia

\section{Crecimiento bacteriano y cuantificación de TNT residual}

Los recuentos poblacionales son valores entre $2,80 \mathrm{E}+08$ y $3,10 \mathrm{E}+08 \mathrm{ufc} / \mathrm{ml}$, los mismos que aumentan progresivamente hasta las 72 horas. (figura 2).

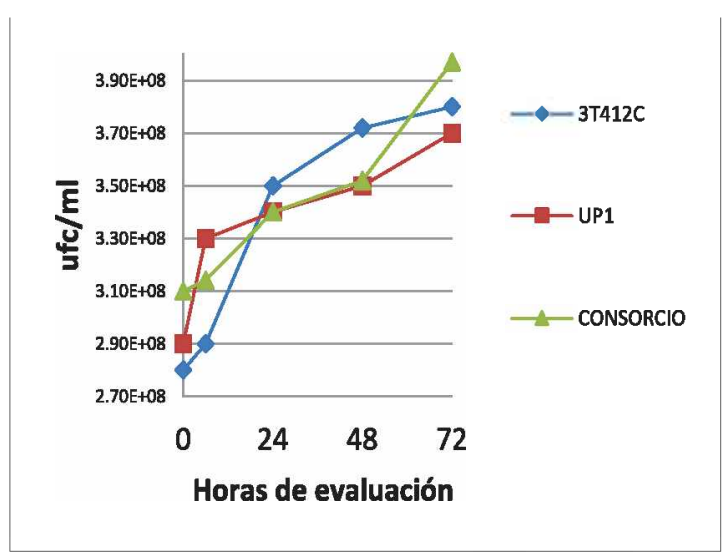

Figura 2. Recuento poblacional bacteriano ( $\mathrm{ufc} / \mathrm{ml})$ empleando cámara PetroffHausser

Fuente: Elaboración propia

Se monitoreó durante 72 horas la concentración de TNT en los medios de cultivo con 3T412C, UP1 y consorcio y un control abiótico (figura 3 ).

Los mayores porcentajes de degradación se registraron a diferentes tiempos, 3T412C degradó el 97, 86\% de TNT en 24 horas, UP1 el 52,41\% y el consorcio $97,9 \%$ en 72 horas (tabla 2).

Los datos obtenidos de la degradación de TNT a las 24 horas se muestran en los cromatogramas de HPLC en $\mathrm{mg} / \mathrm{l}$ (figura 4).

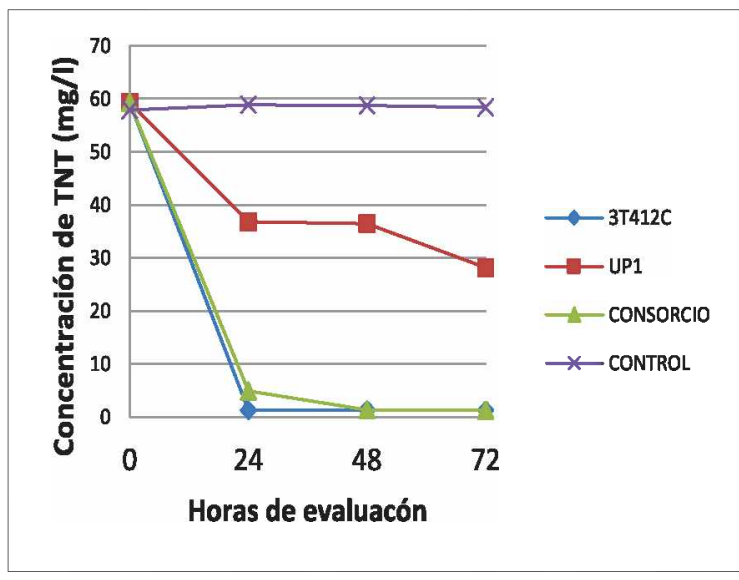

Figura 3. Degradación de TNT en el medio de cultivo de las cepas bacterianas y el consorcio.

Fuente: Elaboración propia

Análisis estadístico: Se procesaron los porcentajes de degradación obtenidos utilizando el diseño completamente aleatorizado con 3 repeticiones en un arreglo factorial de $4 \times 3$, al 0,05 de probabilidad (95\% de confiabilidad).

El análisis de varianza (ANVA), para el "factor cepa", se comparó la razón $\mathrm{F}$ calculada con el Ft de Fisher $(1110,16>3,00)$, que indica que la diferencia de medias de porcentaje de degradación entre las cepas evaluadas y el consorcio son altamente significativas, así como las medias de porcentaje de degradación por cada 24,48 y 72 horas de medición. Además existe interacción entre las cepas y tiempo, es decir, las cepas se comportan de manera diferente en los tiempos evaluados

La prueba de Tuckey realizada a posterior del ANVA, muestra que el consorcio y la cepa 3T412C, estadísticamente, son similares y superiores a UP1 en 72 horas de evaluación. 
Tabla 2. TNT degradado por las cepas y el consorcio seleccionado

\begin{tabular}{|c|c|c|c|c|c|}
\hline \multirow{2}{*}{ CEPA } & \multirow{2}{*}{ PARÁMETRO } & \multicolumn{4}{|c|}{ Tiempo evaluado (horas) } \\
\hline & & 0 & 24 & 48 & 72 \\
\hline \multirow{3}{*}{ 3T412C } & TNT no degradado (mg/l) & 59,23 & 1,27 & 1,28 & 1,22 \\
\hline & TNT degradado (mg/l) & & 57,96 & 57,95 & 58,01 \\
\hline & $\%$ TNT degradado (\%) & & 97,86 & 97,84 & 97,94 \\
\hline \multirow{3}{*}{ UP1 } & TNT no degradado (mg/l) & 59,23 & 36,85 & 36,42 & 28,16 \\
\hline & TNT degradado (mg/l) & & 22,38 & 22,81 & 31,07 \\
\hline & $\%$ TNT degradado (\%) & & 37,87 & 38,50 & 52,45 \\
\hline \multirow{3}{*}{ CONSORCIO } & TNT no degradado (mg/l) & 59,23 & 4,85 & 1,34 & 1,24 \\
\hline & TNT degradado (mg/l) & & 54,38 & 57,89 & 57,99 \\
\hline & $\%$ TNT degradado (\%) & & 91,81 & 97,73 & 97,90 \\
\hline CONTROL & TNT no degradado (mg/l) & 57,89 & 58,86 & 58,72 & 58,32 \\
\hline
\end{tabular}

Fuente: Elaboración propia
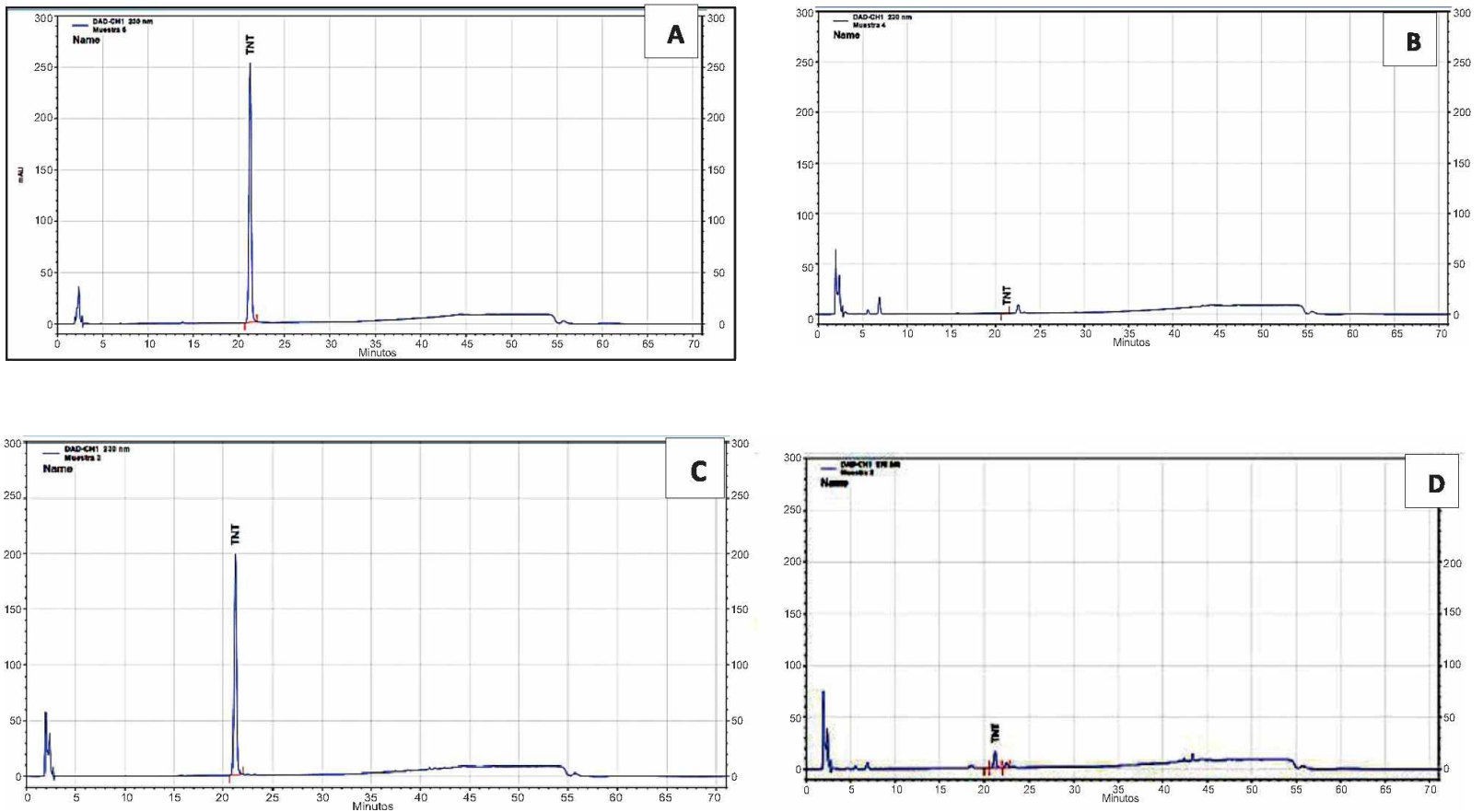

Figura 4. Cromatogramas de HPLC a 24 horas de incubación: Control abiótico (A). 3T412C (B). UP1 (C). Consorcio 3T412C y UP1 (D). Fuente: Elaboración propia

\section{Identificación molecular de las cepas}

La cepa UP1 fue identificada como Serratia marcescens con $99 \%$ de identidad, $100 \%$ de cobertura y un E value de 0.0. La cepa 3T412C fue identificada como Klebsiella oxytoca con $100 \%$ de identidad, $100 \%$ de cobertura y E value de 0,0 (figuras 5 y 6 ). 


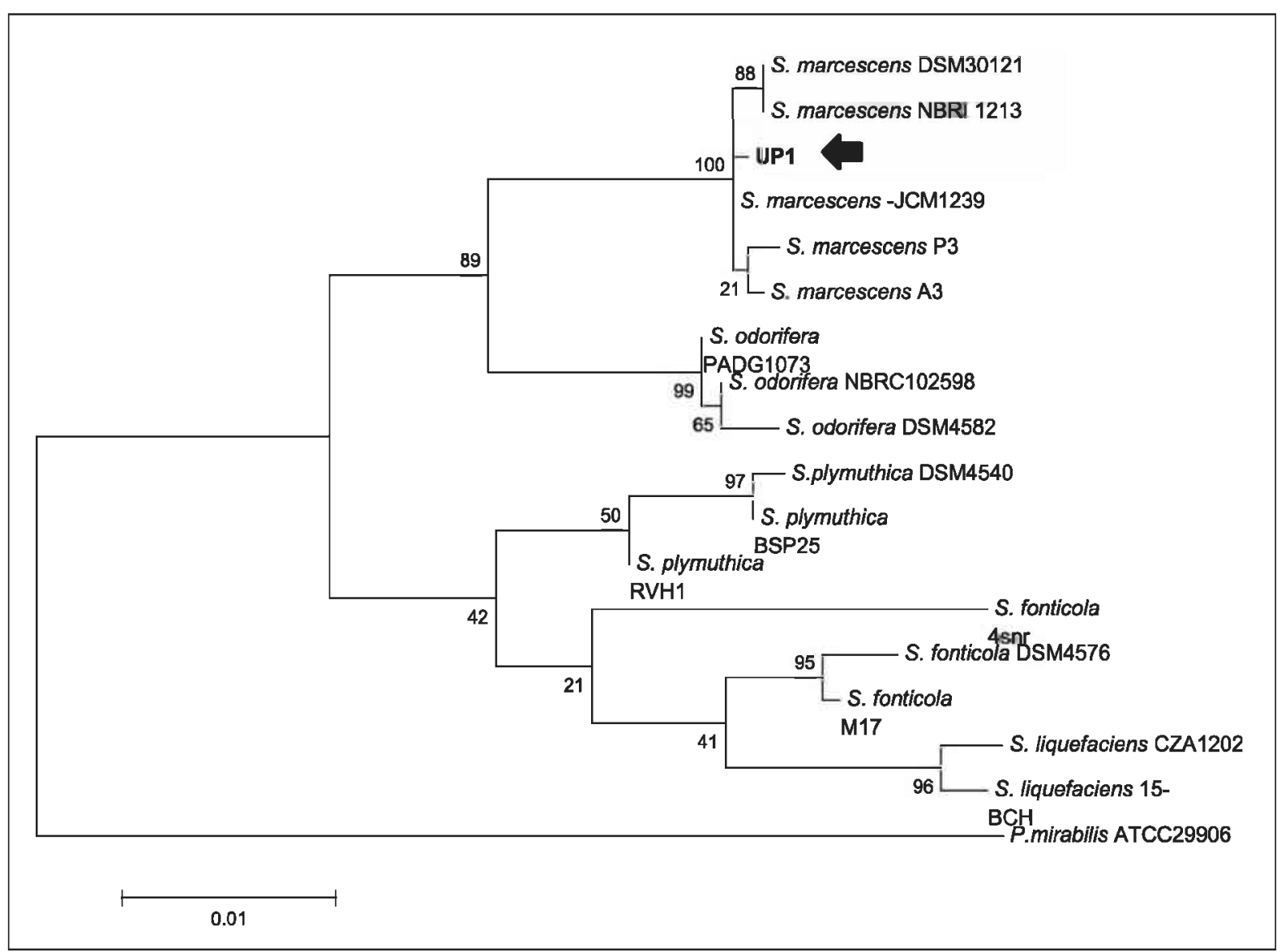

Figura 5. Árbol filogenético de UP1 en la que conforma un clado robusto con Serratia marcescens Fuente: Elaboración propia

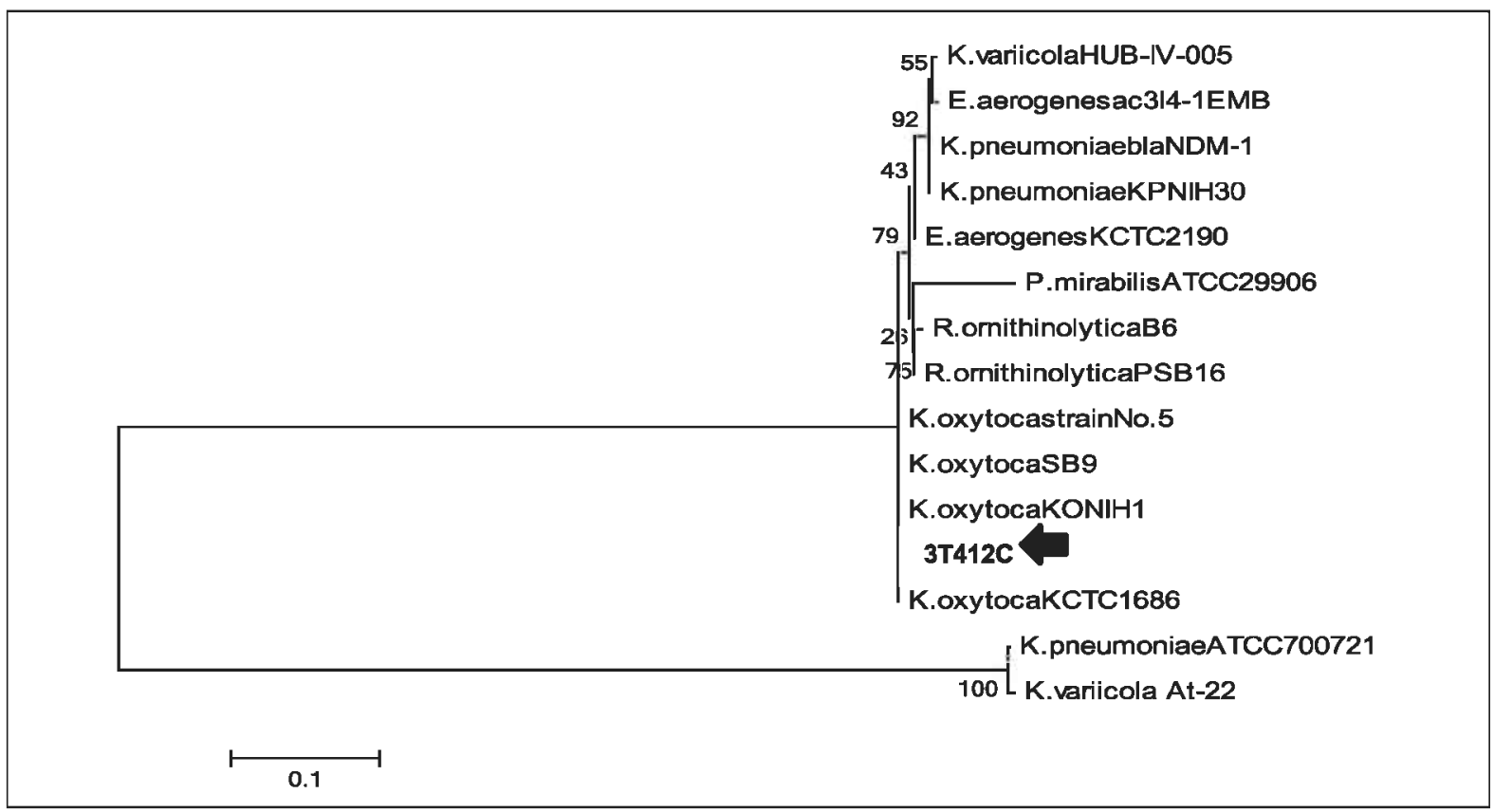

Figura 6. Árbol filogenético de 3T412C que forma un clado con Klebsiella oxytoca

Fuente: Elaboración propia 


\section{DISCUSIÓN}

Identificación de las cepas

Del alineamiento de las secuencias del gen ARNr 16S con la base de datos del Genbank, se obtuvo un $100 \%$ de identidad de 3T412C con Klebsiella oxytoca y $99 \%$ de identidad para UP1 con Serratia marcescens; sin embargo, esta última cepa no presentó pigmentación roja, sino crema. Según el Manual de bacteriología sistemática de Bergey, Serratia marcescens puede presentar un color blanco, rosa o incluso rojo intenso en su morfología colonial, ya que produce pigmentos no difusible insoluble en agua llamada prodigiosina (Williams et al., 1967). Esta particularidad de ausencia de color la reporta también Denis (1971) que aisló cepas a partir de agua de mar que pertenecieron a biotipos de Serratia marcescens pigmentados y no pigmentados.

\section{Crecimiento en Medio Mínimo}

Una característica adicional observada en la experimentación fue el cambio de color a amarillo en el medio de cultivo, tal como reporta Villegas (2009). Investigaciones realizadas por Nyanhongo et al. (2008) postulan que esta coloración se presenta cuando se acumulan en el medio subproductos de la degradación como 2-aminodinitritolueno y 4aminodinitrotolueno, los cuales son producidos por géneros como Bacillus, Desulfovibrio (Kulkarni et al., 2007), Pseudomonas sp. (Park et al., 2002) y algunos consorcios microbianos de bacterias Gram negativas (Kulkarni et al., 2007). Esta característica correspondió a UP1 y el consorcio que mostraron un viraje a crema amarillento tenue al degradar el TNT, 3T412C mantuvo su coloración crema sin variaciones perceptibles tras 72 horas de incubación.

Chien et al. (2014) hace uso de glucosa $1 \%$ como fuente de carbono adicional al medio mínimo con TNT; sin embargo, no se generaron diferencias significativa con el medio mínimo sin glucosa. En los resultados de esta investigación, se hace uso del succinato como fuente de carbono adicional, pero podría escindirse de este elemento para los nuevos estudios.

\section{Liberación de nitritos}

La detección de nitritos en el medio podrían indicar la ruta metabólica empleada durante el proceso de degradación (García, 2011) ya que las bacterias en condiciones aerobias pueden reducir 2 de los 3 grupos de nitritos de la molécula de TNT, el tereer grupo requiere de condiciones anaeróbicas (Esteve et al., 2001 ); sin embargo, son necesarias la prueba de detección de otros metabolitos como el 4amDNT y 2,6 DNT tal como lo presenta Varón (2012).

La variación de la detección en el medio de cultivo de este compuesto podría deberse a la continua transformación del mismo a nitrato y su rápida incorporación de estos al metabolismo de las bacterias (Esteve y Ramos, 1998; Esteve et al., 2000), lo cual podría impedir una acumulación de nitritos en el medio, tal como se observó para 3T412C que, a las 24 horas, presentó una producción de $0,4 \mathrm{mg} / \mathrm{l}$; pero en 48 horas, no se detectó. El consorcio tuvo un comportamiento similar, mas, a las 48 horas, se detectó $0,1 \mathrm{mg} / \mathrm{l}$ de nitrito que a las 72 horas se consumió totalmente. Contrariamente sucedió para UP1, el cual presentó una producción de $1,5 \mathrm{mg} / 1$ en 72 horas, lo cual indica que no estaba siendo metabolizado por la bacteria. Se recomienda que el nitrito liberado no sea considerado como única variable a medir para la degradación de TNT.

\section{Conformación del consorcio y evaluación de la degradación de TNT}

La conformación del consorcio en esta investigación corresponde a un tipo de consorcio definido formado en laboratorio, esta clase de consorcio es ampliamente utilizado en estudios de biorremediación y se caracteriza, porque es reproducible (García, 2011) y se conoce la capacidad degradadora de cada uno de sus miembros. El antagonismo fue descartado por las pruebas de enfrentamiento dual recomendadas por Varón (2012), ya que no se formó halo de inhibición durante la evaluación del crecimiento en medio sólido.

Aunque existen reportes que afirman que la degradación en consorcios es mejor en términos de porcentaje y reducción del tiempo (Antolinez et al., 2001); para este caso, no se mostró tal efecto, pues tras 24 horas de evaluación 3T412C mostró mayor degradación que el consorcio y que UP1, esto podría atribuírsele a una etapa de reconocimiento de metabolitos entre las bacterias, ya que los consorcios se caracterizan porque pueden realizar funciones metabólicas más complejas en comparación a la actividad metabólica realizada por uno solo.

Sin embargo, a las 48 horas, tanto el consorcio como 3T412C, mostraron degradación homogénea de TNT, lo que podría fundamentarse en estabilización del consorcio por la presencia de señales moleculares que pueden activar diferentes rutas metabólicas para la generación de subproductos que pueden ser utilizados por los miembros del consorcio y la producción de surfactantes que potenciaron la degradación en el consorcio tras ese tiempo. En tal sentido, se recomienda realizar las pruebas de inhibición antes de combinarse antes las cepas.

Para saber cómo la comunidad bacteriana interactúa en el tiempo, hace falta un análisis de la comunidad y su caracterización genotípica como lo presenta García (2011), en donde evalúa la recuperación de la capacidad degradadora de TNT y PETN de un consorcio bacteriano; sin embargo, el autor encontró que la capacidad degradadora de los consorcios formados disminuyó con el tiempo; además, es importante mencionar que se reportaron géneros como Burkholderia, Achromobacter, Cupriavidus y Comamonas, los que a partir de una concentración de $150 \mathrm{mg} / 1$ degradaron $93,37 \%$ de TNT tras 20 días de 
incubación en el tratamiento usando como fuente de carbono a glucosa, glicerol, citrato y acetato, sin embargo en este trabajo el consorcio formado por Klebsiella oxytoca 3T412C y Serratia marcescens UP1 logró la degradación del $97,9 \%$ en 72 horas usando únicamente a succinato como fuente de carbono.

Además Varón (2012) reporta que un consorcio formado por Pseudomonas oleovorans y Shinella kummerowiae no superó el $62 \%$ de degradación del TNT tras 120 horas de incubación y una concentración inicial de aproximadamente $100 \mathrm{mg} / \mathrm{l}$, donde esta mezcla presentó un promedio del porcentaje de degradación de las dos cepas en su estado individual.

El género Klebsiella ha sido reportada como degradante de TNT. Investigaciones como la de Chang et al., (2002) reportan que una cepa de Klebsiella sp C1 aislada a partir de lodos activados obtenidos de la planta de tratamiento de Chuncheon - Korea, creció rápidamente en medio de cultivo mínimo en presencia de 100 y $200 \mathrm{mg} / \mathrm{L}$ de TNT, los que fueron degradados en 6 horas; sin embargo, su aislamiento fue con un aumento progresivo de la concentración de TNT de 10 a $300 \mathrm{mg} / \mathrm{l}$ durante 6 meses. Es así que para esta misma cepa se ha reportado la presencia de nitroreductasa tipo I (Hyoun-Young et al., 2005), lo que le permite degradar este tipo de explosivo. Además, Litake et al. (2005) reporta a un aislado clínico de Klebsiella pneumoniae como degradador del $100 \%$ de TNT en 30 horas a partir de 50,40 y $20 \mathrm{mg} / 1$ de TNT.

Por otro lado, Serratia marcescens UP1, aunque mostró un bajo porcentaje de degradación de $42,9 \%$ en promedio tras 72 horas es reportado por Montpas et al. (1997) como degradador de $50 \mathrm{mg} / \mathrm{l}$ de TNT tras 48 horas, las discrepancias podrián deberse a que esta última cepa fue aislada de suelo impactado con TNT.

\section{CONCLUSIÓN}

Se identificaron, molecularmente, a Klebsiella oxytoca 3T412C y Serratia marcescens UP1 que degradaron $97,87 \%$ y $42,94 \%$ de TNT respectivamente en 72 horas. El consorcio formado por la unión de estas cepas degradó el 95,81\% de TNT en el mismo tiempo. Sin embargo, Klebsiella oxytoca 3T412C y el consorcio presentaron estadísticamente el mayor porcentaje de biodegradación, lo que demuestran el potencial de estos microorganismos para usarse en procesos de biorremediación

\section{REFERENCIAS BIBIBLIOGRÁFICAS}

Antolinez, N., Acero, S., Martinez P., Bernal J. (2001) Degradación del Malathion por Bacterias aisladas de la Bahia de Cartagena. Paper presented at the $I V$ Simposio Internacional de Desarrollo Sustentable/Regulación de la Fertilidad en Agroecosistremas de los Andes Tropicales. Venezuela.
Chang, C., Kim, H., Kang, Y., Bae, K., Song, H-G. (2002). Transformation of 2,4,6 Trinitrotoluene in various conditions by Klebsiella sp. Strain C1 Isolated from Activated Sludge. The Journal of Microbiology. 193-198.

Chien, C., Kao, C., Chen, D., Chen, S. y Chen, C. (2014). Biotransformation of trinitrotoluene (TNT) by Pseudomonas spp. isolated from a TNT-contaminated environment. Environ Toxicol Chem. 33, 1059-1063.

Cho, Y., Bheong-U., y Oh, K. (2008). Simultaneous degrada-tion of nitroaromatic compounds TNT, RDX, atrazine, and simazine by Pseudomonas putida HK-6 in bench-scale bioreactors. J Chem Technology Biotech. 83,1211-1217.

Denis, F. (1971). Contribution a l'etude des bacteries Mterotrophes du milieu marin: Inventaire de 2700 souches. (PhD Thesis). Université Poitiers, France.

Durán, Y. (2013). Caracterización molecular de bacterias degradadoras de pentaeritritol tetranitrato (PETN) aisladas de ambientes mineros y evaluación de su eficiencia de degradación. (tesis de pregrado). Universidad Nacional Mayor de San Marcos, Lima, Perú.

Environmental Protection Agency (EPA). (2001). Handbook on the management of ordnance and explosives at closed, transferring, and transferred ranges and other sites.

Esteve, A., Caballero, A., y Ramos, J. (2001). Biological degradation of $2,4,6$ Trinitrotoluene. Microbiology and Molecular Biology Reviews. 65, 335-352.

Esteve, A., Lucchesi, G., Philipp, B., Schink, B., Ramos, J. (2000). Respiration of 2,4,6trinitrotoluene by Pseudomonas strain JLR 11. J. Bact. 182, 1352-1355.

Esteve, A., Ramos, J.L. (1998). Metabolism of 2,4,6 -trinitrotolueno by Pseudomonas sp JLR11. Environmental Science \& Technology. 32, 3802-3808.

Fiorella, P. y Spain, J.C. (1997). Transformation of 2,4,6-Trinitrotoluene by Pseudomonas pseudoalcaligenes JS52. Applied Environmental Microbiology. 63, 2007-2015.

Fritsche, W., Hofrichter, M. (2000). Aerobic degradation by microorganisms. En: Klein, J. (Ed.), Biotechnology, Environmental Processes II e Soil Decontamination. 11b, $146-164$

Hyoun-Young K., Hong-Gyu S. (2005). Purification and characterization of NAD $(P) H-$ dependent nitroreductase I from Klebsiella sp. $\mathrm{C} 1$ and enzymatic transformation of $2,4,6$-trinitrotoluene. Applied Microbiology and Biotechnology. 68, 766-773. 
Kulkarni M. y Chaudhari A. (2007). Microbial remediation of nitro-aromatic compounds: An overview. Journal of Environmental Management. 85, 496-512.

Montpas, S., Samson, J., Langlois, É., Lei, J., Piché, Y. y Chênevert R. (1997). Degradation of 2,4,6-trinitrotoluene by Serratia marcescens. Biotechnology Letters. 19(3), 291-294

Nyanhongo, G., Aichernig, N., Ortner, M., Steiner W., y Guebitz G. (2008). Incorporation of 2,4,6trinitrotoluene (TNT) transforming bacteria into explosive formulations. Journal of Hazardous Materials. 89(43), 1-6.

Oh, B., Shea, P., Grijber, R., Vasilyeva, G., y Sarath, G. (2003). TNT biotransformation and detoxification by Pseudomonas aeruginosa strain. Biodegradation. 14, 309-319.

Orjuela, P., Sandon, A., Franco, M., y Martinez, M. (2003). Evaluación de cepas antagónicas de actinomicetos y de Trichoderma spp. aislados a partir de suelos de cultivo de arroz (Oryza sativa) para el control de Rhizoctonia solani. Revistas Mundo Microbiológico. 2(2),9-14.

Pandey, G. y Rakesh, K. (2002). Bacterial Chemotaxis toward Environmental Pollutants: Role in Bioremediation. Applied and Environmental Microbiology. 68(12), $5789-5795$.

Pak, J.; Knoke, K.; Noguera, D.; Fox, B.; Chambliss, G. (2000). Transformation of 2,4,6trinitrotoluene by Purified Xenobiotic Reductase B from Pseudomonas fluorescens I-C. Applied and Environmental Microbiology. 66, 4742-4750.
Stenuit, B., Eyers, L., Rozenberg, R., Habib-Jiwan, J., Matthijs, S., Cornelis, P. (2009). Denitration of 2,4,6-Trinitrotoluene in aqueous solutions using small-molecular-weight catalyst(s) secreted by Pseudomonas aeruginosa ESA-5. Environmental Science \& Technology. 43(6), 2011-2017.

Varón, H. (2012). Efecto del pH y la temperatura en la degradación del 2,4,6 Trinitrotolueno, por bacterias aisladas de sitios con presencia de explosivos. (tesis de maestría). Universidad de la Sabana, Bogotá, Colombia.

Villegas, S. (2009). Aislamiento de microorganismos degradadores de 2,4,6-trinitrotolueno (TNT) a partir de ambientes contaminados con explosivos. (tesis de pregrado). Pontificia Universidad Javeriana, Bogotá, Colombia.

Watrous, M., Clark, S., Kutty, R., Huang, S., Rudolph, F., Hughes, J., y Bennett, G. (2003). 2,4,6Trinitrotoluene Reduction by an Fe-Only Hydrogenase in Clostridium acetobutylicum. Applied Environmental Microbiology. 69, 1542-1547.

Williams, R., Rathbone, D., Scrutton, N., y Bruce, N. (2004). Biotransformation of explosives by the old yellow enzyme family of flavoproteins. Applied Environmental Microbiology. 70, 3566-3574.

Ziganshin A., Gerlach, R., Borch, T., Naumov A., y Naumova R. (2007). Production of Eight Different Hydride Complexes and Nitrite Release from 2,4,6-Trinitrotoluene. Yarrowia lipolytica. Applied Environmental Microbiology. 73, 7898-7905. 